This is the peer reviewed version of the following article: Chem. Eur. J. 2014, 20, 13089 - 13093, which has been published in final form at http://onlinelibrary.wiley.com/doi/10.1002/chem.201404215/abstract

This article may be used for non-commercial purposes in accordance with http://olabout.wiley.com/WileyCDA/Section/id-

820227.html

\title{
Highly Enantioselective Cross-Aldol Reactions of Acetaldehyde Mediated by a Dual Catalytic System Operating under Site Isolation
}

\author{
Xinyuan Fan, ${ }^{[\mathrm{a}]}$ Carles Rodríguez-Escrich, ${ }^{[\mathrm{a}]}$ Shoulei Wang, ${ }^{[\mathrm{a}]}$ Sonia Sayalero, ${ }^{[\mathrm{a}]}$ and Miquel A. Pericàs* ${ }^{[\mathrm{a}, \mathrm{b}]}$
}

[a] X. Fan, Dr. C. Rodríguez-Escrich, S. Wang, Dr. S. Sayalero, Prof. Dr. M. A. Pericàs

Institute of Chemical Research of Catalonia (ICIQ) Avinguda Països Catalans 16, 43007, Tarragona (Spain)

Fax : (+34) 977-920-243. E-mail: mapericas@iciq.es

[b] Prof. Dr. M. A. Pericàs

Departament de Química Orgánica, Universitat de Barcelona, 08080 Barcelona (Spain)

Abstract: Polystyrene-supported (PS) diarylprolinol catalysts $\mathbf{1} \mathbf{a}(\mathrm{Ar}=$ phenyl) and $\mathbf{1} \mathbf{b}(\mathrm{Ar}=3,5$-bis(trifluoromethyl)phenyl) have been developed. Operating under site-isolation conditions, PS-1 a/1 b worked compatibly with PS- bound sulfonic acid catalyst 2 to promote deoligomerization of paraldehyde and subsequent cross-aldol reactions of the resulting acetaldehyde in one pot, affording aldol products in high yields with excellent enantioselectivities. The effect of water on the performance of the catalytic system has been studied and its optimal amount ( 0.5 equiv) has been determined. The dual catalytic system (1/2) allows repeated recycling and reuse (10 cycles). The potential of this methodology is demonstrated by a two- step synthesis of a phenoperidine analogue (68\% overall yield; $98 \%$ ee) and by the preparation of highly enantioenriched 1,3-diols 4 and 3-methylamino-1-arylpropanols 5, key intermediates in the synthesis of a variety of druglike structures.

The aldol reaction has attracted plenty of interest due to its pivotal role in organic synthesis.[1] Among the various methods available to carry out this reaction enantioselectively, the organocatalytic methods stand out for several reasons: 1) under extremely mild reaction conditions excellent stereocontrol can be achieved in up to two newly formed stereocenters, 2) no prefunctionalization of any of the reactants is required, and 3) the reactions take place in a metal-free environment, which avoids product contamination with toxic metal derivatives. ${ }^{[2]}$ Therefore, important developments have been achieved since the first report on the direct asymmetric intermolecular aldol reaction catalyzed by proline in 2000. The use of acetaldehyde (the simplest enolizable aldehyde), however, has been a great challenge due to its high reactivity and its inherent tendency to oligomerize. ${ }^{[4]}$ In 2008, Hayashi and co-workers reported the first asymmetric aldol reaction of acetaldehyde with good yields and excellent enantioselectivities by using diaryprolinol as the catalyst. ${ }^{[5]}$ Shortly after, the same reaction was tested with a diamine catalyst to afford aldol products with varying yields (34-99\%) and enantioselectivities (69-92\%). Recently, a water compatible diarylprolinol derivative has been reported to promote this reaction in brine, affording aldol products in good yields and ee's.

Despite the excellent results in these reports, some problems remain unsolved in this reaction, especially from the practical point of view. For instance, the low boiling point of acetaldehyde $\left(21^{\mathrm{O}} \mathrm{C}\right)$ seriously hampers its transportation, storage, and handling, therefore increasing cost and energy consumption. From the reaction perspective, the tendency to oligomerization and high reactivity of acetaldehyde is detrimental, since side reactions are common. To overcome these drawbacks, an interesting example was reported recently using vinyl acetate as acetaldehyde precursor in cross-aldol reactions. The recorded enantioselectivities, however, were very low $\left(10-20 \%\right.$ ee). ${ }^{[8]}$ On the other hand, the high catalyst loading required for the reaction to take place in a reasonable time makes desirable the development of a recyclable catalytic system.

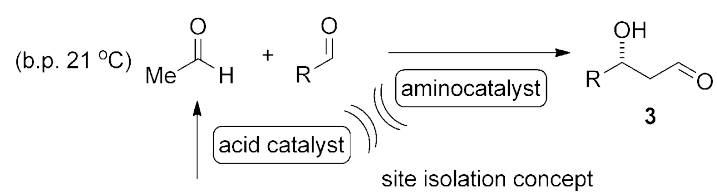

(b.p. $123^{\circ} \mathrm{C}$<smiles>CC1OC(C)OC(C)O1</smiles> 
Scheme 1. Cascade deoligomerization plus cross-aldol reaction mediated by two incompatible catalysts operating under site isolation.

We have recently introduced a "wolf-and-lamb" reaction system ${ }^{[10]}$ for the asymmetric Michael reaction of acetaldehyde. In our approach, ${ }^{[11]}$ cheap and easy-to-handle paraldehyde $\left(3.7 €\right.$ per mol; b.p. $\left.123{ }^{\circ} \mathrm{C}\right)$ is employed as a convenient source of acetaldehyde, which is slowly generated by acid-catalyzed deoligomerization (polystyrene-bound sulfonic acid). In this way, the concentration of the reactive species in the reaction media remains low and the problems mentioned above are avoided. Acetaldehyde generated in this way is able to undergo a Michael reaction mediated by a polystyrene-supported (PS)supported diphenylprolinol TIPS (triisopropylsilyl) ether, furnishing the addition products in good yield with excellent enantioselectivity.

The implementation of this approach required the operation of the two catalysts under strict site isolation ${ }^{[12]}$ conditions (tea bag) to avoid their mutual deactivation. In light of these results, we speculated that application of this concept could provide a convenient solution for the asymmetric cross-aldol reactions of acetaldehyde (Scheme 1).

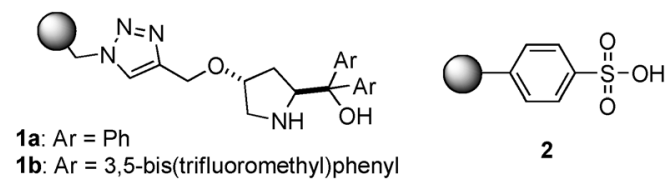

Figure 1. Catalysts used in this study.

In view of precedents with homogeneous catalysts, we selected and prepared the new PS-diarylprolinols 1 a-b (Figure 1) to mediate the cross-aldol reaction in combination with the same PS-bound sulfonic acid 2 , already used to deoligomerize paraldehyde for Michael additions. ${ }^{[11]}$ For the optimization of reaction conditions, the cascade deoligomerization plus crossaldol reaction between 4-nitrobenzaldehyde and paraldehyde leading after reduction to $\mathbf{4 e}$ was selected (Table 1). The dual catalytic system $\mathbf{1} \mathbf{a} / \mathbf{2}$ was rather inefficient in $\mathrm{CH}_{2} \mathrm{Cl}_{2}$, with low conversion and moderate ee recorded after $26 \mathrm{~h}$ (Table 1 , entry 1). In contrast, $\mathbf{1} \mathbf{b}$ provided much higher enantioselectivities in this solvent, although conversion remained low (entry 2). The use of $\mathbf{1} \mathbf{b}$ was adopted and, to improve conversion, several solvents were screened. Surprisingly, no conversion was

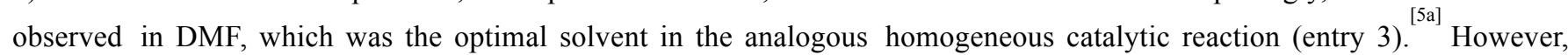
increased conversion and ee were recorded in $\mathrm{THF}, \mathrm{MeCN}$, and $\mathrm{THF} / \mathrm{MeCN}$ or even under neat conditions (entries 4-8). Particularly in MeCN, $64 \%$ conversion and $98 \%$ ee were achieved. In full agreement with our working hypothesis, no conversion was observed when the reaction was carried out with a soluble acid, in this case pTsOH, instead of catalyst $\mathbf{2}$, due to salt formation with $\mathbf{1} \mathbf{b}$ (entry 6). Higher conversions could be achieved when increasing the temperature in $\mathrm{MeCN}$, but at the cost of lowering the enantioselectivity of the reaction (entry 9). Water (entry 10) and brine (entry 11) were also tested, but almost no conversion was observed in both cases. To evaluate the impact of moisture on the performance of the dual catalytic system, the reaction was carried out in strictly anhydrous media (glovebox, dry MeCN), but only $8 \%$ conversion was observed (compare entries 12 and 7). These results encouraged us to quantify the influence of added water to the reaction media on the performance of the reaction. ${ }^{[13]}$ While its presence in small amounts entailed an increase in conversion (entries 13,14), larger quantities were found to slow down the process (entry 15), albeit enantioselectivity remained unchanged. It was eventually found (entry 16) that excellent conversion (91\%) and enantioselectivity (98\%) could be achieved with $20 \mathrm{~mol} \%$ of $\mathbf{1} \mathbf{b}$ and 0.5 equivalents of water as an additive. Most likely, water is required to reactivate catalyst $\mathbf{1} \mathbf{b}$, which might be deactivated by slow oxazolidine formation with any of the aldehydes present in the reaction mixture (vide infra). Noteworthy, the combined use of $\mathbf{1} \mathbf{b} / \mathbf{2}$ under these conditions does not require the physical separation of the two resins, as was the case for the combined use of the silyl ether of $\mathbf{1}$ a and $\mathbf{2}$ in Michael additions of acetaldehyde. 
Table 1. Cascade paraldehyde deoligomerization and asymmetric cross-aldol reaction of 4-nitrobenzaldehyde with paraldehyde mediated by $\mathbf{1} \mathbf{b} / \mathbf{2}^{[\mathrm{a}]}$

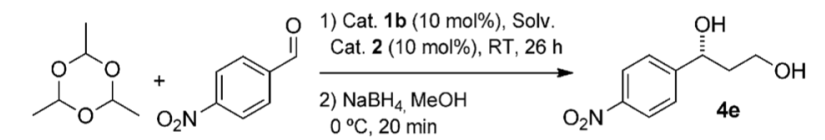

\begin{tabular}{lllcc} 
Entry & Solvent & \multicolumn{4}{l}{ Water content Conv. $[\%]^{[\mathrm{b}]}$ ee $[\%]^{[\mathrm{c}]}$} \\
\hline $1^{[\mathrm{d}]}$ & $\mathrm{CH}_{2} \mathrm{Cl}_{2}$ & - & 19 & 73 \\
2 & $\mathrm{CH}_{2} \mathrm{Cl}_{2}$ & - & 15 & 94 \\
3 & $\mathrm{DMF}$ & - & 0 & - \\
4 & $\mathrm{Neat}$ & - & 47 & 94 \\
5 & $\mathrm{THF}$ & - & 59 & 98 \\
$6^{[\mathrm{e}]}$ & $\mathrm{THF}$ & - & 0 & n.d. \\
7 & $\mathrm{MeCN}$ & - & 64 & 98 \\
8 & $\mathrm{THF} / \mathrm{MeCN}$ & - & 59 & 98 \\
$9^{[\mathrm{f}]}$ & $\mathrm{MeCN}$ & - & 88 & 78 \\
10 & $\mathrm{H} 2 \mathrm{O}$ & - & 4 & - \\
11 & $\mathrm{brine}$ & - & 0 & - \\
$12^{[\mathrm{g}]}$ & $\mathrm{MeCN}$ & 0 & 8 & n.d. \\
13 & $\mathrm{MeCN}$ & 0.5 & 74 & 98 \\
14 & $\mathrm{MeCN}$ & 1.0 & 71 & 98 \\
15 & $\mathrm{MeCN}$ & 5.0 & 65 & 98 \\
$16^{[\mathrm{h}]}$ & $\mathrm{MeCN}$ & 0.5 & 91 & 98 \\
\hline
\end{tabular}

[a] The reaction was carried out with 4-nitrobenzaldehyde $(0.1 \mathrm{mmol})$, paraldehyde $(0.2 \mathrm{mmol}), \mathbf{1 b}(10 \mathrm{~mol} \%)$, and $2(10 \mathrm{~mol} \%)$ in $0.1 \mathrm{~mL}$ solvent. [b] By ${ }^{1} \mathrm{H}$ NMR spectroscopy. [c] By HPLC analysis. [d] Compound $\mathbf{1}$ a was used instead of $\mathbf{1} \mathbf{b}$. [e] pTsOH was used instead of $\mathbf{2}$. [f] At $50{ }^{\circ} \mathrm{C}$. [g] In the glovebox. [h] $20 \mathrm{~mol} \%$ of $\mathbf{1} \mathbf{b}$ was used.

The scope of the cross-aldol reaction was studied next under the optimized reaction conditions, and the results are listed in Table 2. It was established that benzaldehydes with either ortho, meta, or para electron-withdrawing substituents afforded the desired cross-aldol products with generally good yields and excellent enantioselectivities (Table 2, entries 1-9). In addition, disubstituted aromatic aldehydes, such as 2,4-dichlorobenzaldehyde and 2-methoxy-4-nitro-benzaldehyde, were also tolerated (entries 10 and 11). Benzaldehyde and aromatic aldehydes bearing electron-donating substituents, in turn, are not reactive when using this method.

From the mechanistic point of view, the whole procedure involves two separate reactions that take place in a cascade manner. First, paraldehyde is deoligomerized into acetaldehyde, a process catalyzed by the supported Brønsted acid $\mathbf{2}$. Then acetaldehyde condenses with catalyst $\mathbf{1} \mathbf{b}$ to generate the enamine intermediate, which reacts with the corresponding aldehyde to afford the product. A catalyst off-cycle, regulated by the addition of water to the reaction media also needs to be considered. In Scheme 2, oxazolidine formation is shown for the aldol product $\mathbf{3}$ e, but similar parasitic species can also be proposed with acetaldehyde or the aromatic aldehyde involved in the cross-aldol reaction.

From a practical perspective, one of the main advantages offered by heterogenized catalysts is their easy recovery by simple filtration and the consequent possibility of reusing In this respect, the fact of recycling two different polystyrene-supported catalysts without having to separate them is of particular interest. Therefore, the recyclability of the $\mathbf{1}$ b/2 dual catalyst system was tested in the cross-aldol reaction with 4-nitrobenzaldehyde using different protocols. It was found that thoroughly drying the resin between cycles improved the performance on the forthcoming runs. However, the system was still suffering from a gradual deactivation. We then hypothesized that an oxazolidine off-cycle species might be responsible for sequestering part of the catalytically active species $\mathbf{1 b}$ (see Scheme 2 and the Supporting Information). To circumvent this problem, after each cycle, the combined resins were washed with $\mathrm{AcOH}$ in moist $\mathrm{MeCN}$ with the goal of hydrolyzing this parasitic species, thus setting the aminocatalyst free again (see the Supporting Information for details). To our delight, this strategy proved to have a tremendous impact on the reusability of the $\mathbf{1} \mathbf{b} / \mathbf{2}$ combination. Keeping the reaction time constant ( $26 \mathrm{~h}$ ) we could achieve roughly the same results for the first 5 runs. After that, the isolated yield decreased, albeit in a very mild manner. For instance, in the tenth run, the aldol product was still isolated in $56 \%$ yield. Even more remarkably, the enantioselectivity remained constant at $97 \%$ throughout the ten runs (Scheme 3). 
Table 2. Asymmetric cross-aldol reaction of acetaldehyde. ${ }^{[\mathrm{a}]}$<smiles>CC1OC(C)OC(C)O1</smiles>
1) Cat. 1 b (20 mol\%), $\mathrm{H}_{2} \mathrm{O}$ Cat. $2(10 \mathrm{~mol} \%), \mathrm{MeCN}, \mathrm{RT}$ 2) $\mathrm{NaBH}_{4}, \mathrm{MeOH}, 0^{\circ} \mathrm{C}, 20 \mathrm{~min}$

4a-k

\begin{tabular}{|c|c|c|c|c|c|}
\hline Entry & Product & $\mathrm{t}[\mathrm{h}]$ & 4 & Yield $[\%]$ & ee $[\%]^{[c]}$ \\
\hline 1 & & 52 & $4 a$ & 62 & 97 \\
\hline 2 & & 52 & $4 b$ & 40 & 99 \\
\hline 3 & & 28 & $4 c$ & 77 & 99 \\
\hline 4 & & 72 & $4 d$ & 78 & 99 \\
\hline 5 & $\mathrm{O}_{2} \mathrm{~N}^{-}$ & 26 & $4 e$ & 80 & 98 \\
\hline 6 & $\mathrm{Cl}^{-}$ & 52 & $4 \mathrm{f}$ & 28 & 97 \\
\hline 7 & $\mathrm{Br}$ & 72 & $4 g$ & 47 & 97 \\
\hline 8 & $\mathrm{~F}_{3} \mathrm{C}$ & 72 & $4 h$ & 68 & 97 \\
\hline 9 & $\mathrm{NC}^{-}$ & 28 & $4 i$ & 61 & 98 \\
\hline 10 & $\mathrm{Cl}^{-}$ & 52 & $4 \mathbf{j}$ & 63 & 98 \\
\hline 11 & $\mathrm{O}_{2} \mathrm{~N}^{-}$ & 28 & $4 k$ & 89 & 96 \\
\hline
\end{tabular}

[a] Reactions were carried out with aldehyde $(0.2 \mathrm{mmol})$, paraldehyde (0.4 mmol), $\mathrm{H}_{2} \mathrm{O}(0.1 \mathrm{mmol}), \mathbf{1 b}(20 \mathrm{~mol} \%)$, and $\mathbf{2}(10 \mathrm{~mol} \%)$ in 0.2 $\mathrm{mL} \mathrm{MeCN}$. [b] Isolated yield. [c] ee was measured by HPLC analysis. 


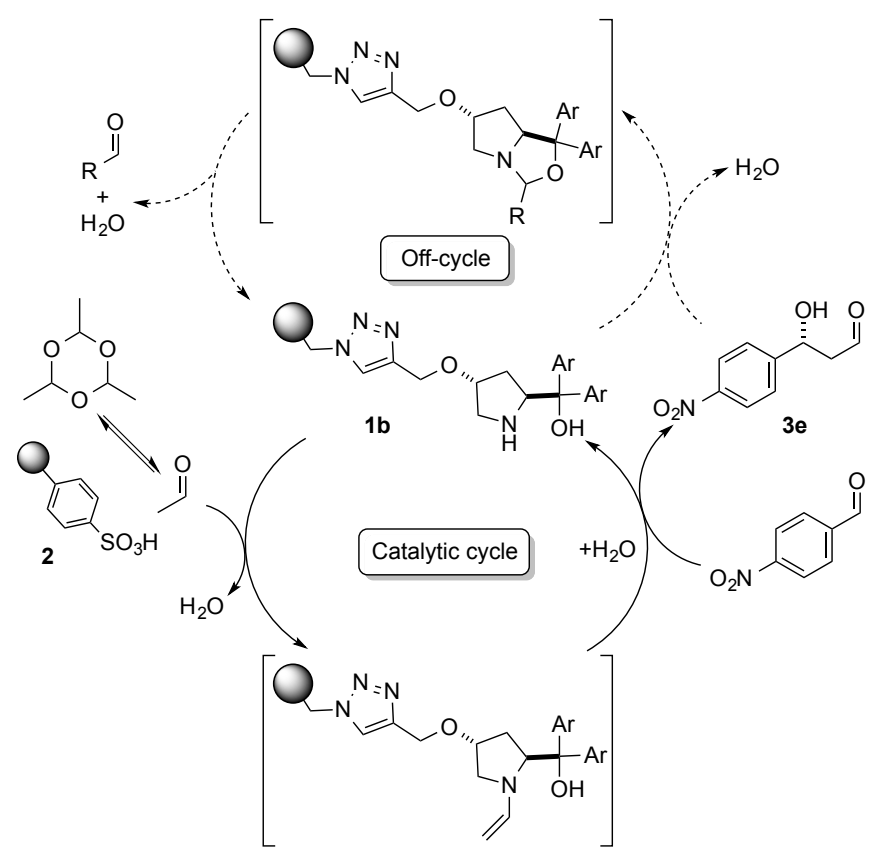

Scheme 2. Schematic mechanistic picture of the paraldehyde deoligomerization plus cross-aldol cascade process mediated by $1 \mathbf{b} / 2$.

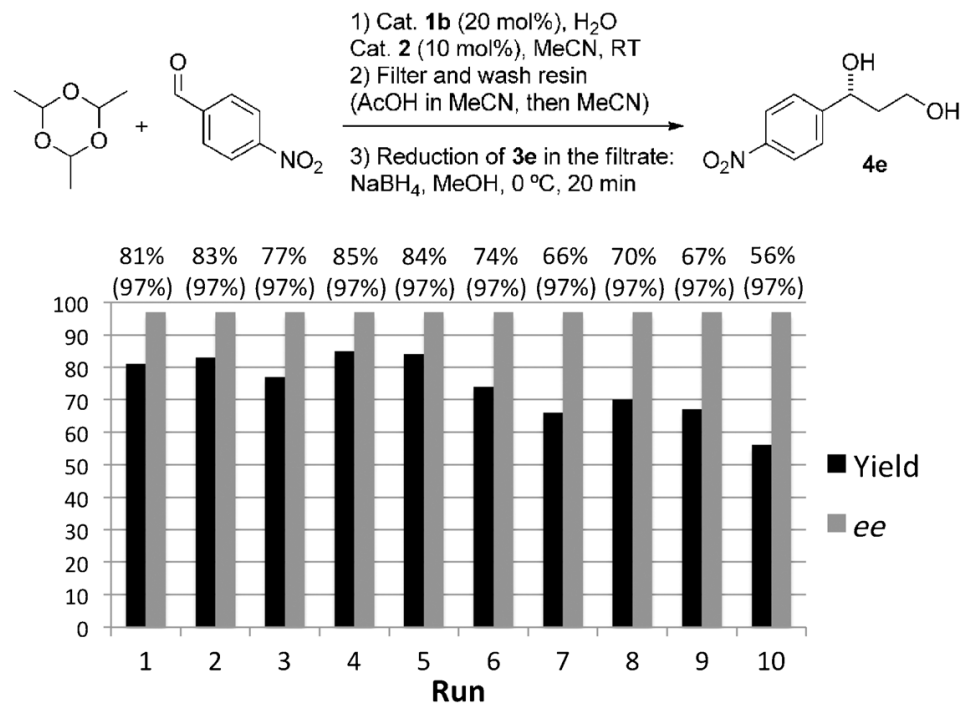

Scheme 3. Recycling tests of the dual catalytic system.

Enantioenriched diols with the general structure 4 are key intermediates in the synthesis of a variety of marketed drugs (Tolterodine, ${ }^{[14]}$ Dapoxetine ${ }^{[15]}$ ) and natural products (Diospongins A and $\mathrm{B}^{[16]}$ ). Amino alcohols $\mathbf{5}$, in turn, are intermediates in the synthesis of important drugs (Atomoxetine, ${ }^{[17]}$ Fluoxetine, ${ }^{[18]}$ Nisoxetine, $^{[18 d]}$ and Duloxetine $\left.{ }^{[18 a, ~ d, ~ e] ~}\right)^{[19]}$ Traditional methods for the preparation of enantioenriched 4 normally involve Sharpless epoxidation of allylic alcohols, ${ }^{[19]}$ and a crossaldol, organocatalytic approach would represent important advantages. ${ }^{[20]}$ Enantiopure amino alcohols 5 have been synthesized from 4 in two steps, ${ }^{[19]}$ but could also be acceded by simple reductive amination from cross-aldol products 3. Taking the cross-aldol reaction of p-nitrobenzaldehyde as an example, we show in Scheme 4 how crude $\mathbf{3 e}$ can be directly converted to amino alcohol 5 e by reductive amination with $\mathrm{MeNH}_{2}$ in good overall yield (71 \%) and excellent ee $(99 \%)$. In a further application, the phenoperidine ${ }^{[21]}$ analogue 6 has been prepared (68\% overall yield, $98 \%$ ee) by reductive amination of crude $\mathbf{3 e}$ with ethyl 4-phenylpiperidine-4-carboxylate and $\mathrm{NaBH}(\mathrm{OAc})_{3}$. Polymer-supported $\mathbf{1}$ b, which could act as a competitive aminating reagent, is conveniently removed by filtration (together with 2) before the reductive amination step. 


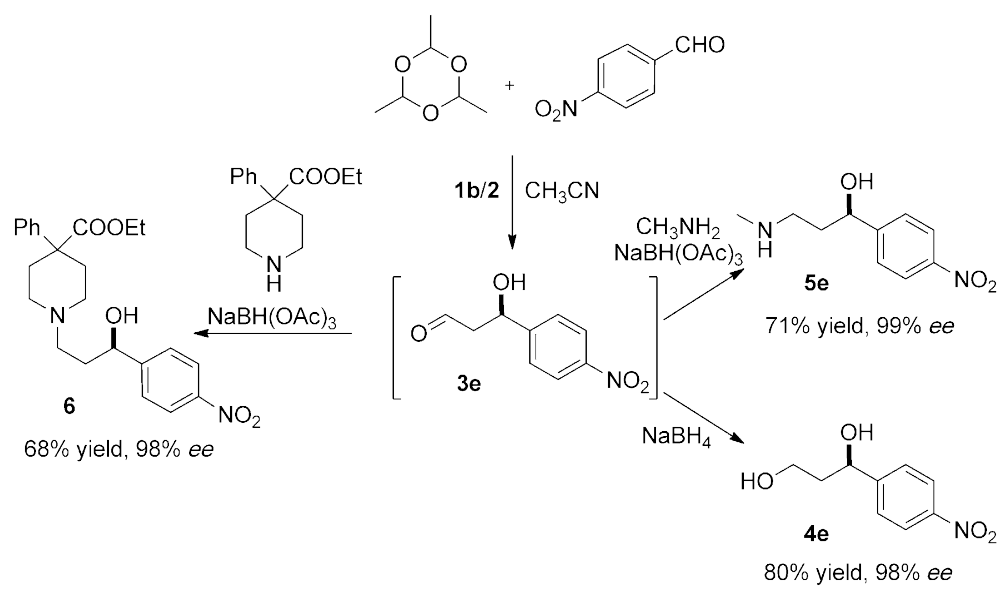

Scheme 4. Synthesis of drug analogues and intermediates from crude cross-aldol adducts 3.

In summary, two polymer-supported catalytic species that would mutually deactivate in solution, define a "wolf-and- lamb" catalytic system suitable for performing, in a sequential manner and in a single reaction pot, the acid-catalyzed deoligomerization of paraldehyde and the highly enantioselective, amine-catalyzed cross-aldol reaction of acetaldehyde with aromatic aldehydes. This dual catalytic system, which exploits the site isolation principle in heterogeneous catalysis, simply relies in the absence of chemical communication between individual polymer beads and does not require any additional permeable barrier. Catalytic activity can be regulated by the addition of small amounts of water to the reaction media, and the whole catalytic system can be recycled and reused at least ten times by simple filtration of the polymer mixture and mild acidic washing to recover full performance. The suitability of the crude cross-aldol products for the straightforward preparation of enantiopure drug analogues highlights the potential of the present methodology in medicinal chemistry.

\section{Experimental Section}

General procedure for the aldol reaction.

Catalyst $1 \mathbf{b}(0.04 \mathrm{mmol}, 20 \mathrm{~mol} \%)$, Catalyst $2(0.02 \mathrm{mmol}, 10 \mathrm{~mol} \%)$ and the aldehyde $(0.2 \mathrm{mmol})$ were mixed in a vial with acetonitrile $(0.2 \mathrm{~mL})$. Then paraldehyde $(0.4 \mathrm{mmol})$ and deionized water $(0.1 \mathrm{mmol})$ were added and the vial was capped and shaken at room temperature. After reaction completion (see Table 2), the mixture was filtered and the resin was washed with methanol $(3 \times 0.5 \mathrm{~mL})$. The filtrates were combined and cooled to $0{ }^{\circ} \mathrm{C}$. Then $\mathrm{NaBH} 4(0.6 \mathrm{mmol})$ was added and the mixture was stirred for $20 \mathrm{~min}$. The reaction was quenched with aqueous $\mathrm{NH}_{4} \mathrm{Cl}(3 \mathrm{~mL})$, and extracted with ethyl acetate ( 3 x $5 \mathrm{~mL}$ ). The organic phases were combined, washed with brine $(2 \mathrm{~mL})$, and dried over $\mathrm{Na}_{2} \mathrm{SO}_{4}$. After solvent removal, products were purified by flash chromatography on silica gel, with hexanes/ethyl acetate mixtures as the eluent.

\section{Acknowledgements}

Financial support from the Institute of Chemical Research of Catalonia (ICIQ) Foundation, MINECO (grant CTQ201238594-C02-01) and DEC Generalitat de Catalunya (Grant 2014SGR827) is gratefully acknowledged. We also thank MINECO for support through Severo Ochoa Excellence Accreditation 2014-2018 (SEV-2013-0319). X.F. thanks the CSC (Chinese Scholarship Council) for the scholarship support. C.R.-E. thanks the AGAUR (Generalitat de Catalunya) for a Beatriu de Pinós B fellowship.

\section{Keywords}

acetaldehyde $\cdot$ cross-aldol $\cdot$ recycling $\cdot$ site-isolation $\cdot$ wolf and lamb

[1] a) R. Mahrwald, Chem. Rev. 1999, 99, 1095-1120; b) T. D. Machajewski, C.-H. Wong, Angew. Chem. Int. Ed. 2000, 39, 1352-1375; c) C. Palomo, M. Oiarbide, J. M. Garcia, Chem. Soc. Rev. 2004, 33, 65-75; d) B. M. Trost, C. S. Brindle, Chem. Soc. Rev. 2010, 39, 1600-1632.

[2] a) C. Allemann, R. Gordillo, F. R. Clemente, P. H.-Y. Cheong, K. N. Houk, Acc. Chem. Res. 2004, 37, 558-569; b) W. Notz, F. Tanaka, C. F. Barbas, Acc. Chem. Res. 2004, 37, 580-591; c) S. Saito, H. Yamamoto, Acc. Chem. Res. 2004, 37, 570579; d) A. P. Brogan, T. J. Dickerson, K. D. Janda, Angew. Chem. Int. Ed. 2006, 45, 8100-8102; e) D. Enders, C. Grondal, M. R. M. Hüttl, Angew. Chem. Int. Ed. 2007, 46, 1570-1581; f) G. Guillena, C. Nájera, D. J. Ramón, Tetrahedron: Asymmetry 2007, 18, 2249-2293; g) V. Bisai, A. Bisai, V. K. Singh, Tetrahedron 2012, 68, 4541-4580; h) M. M. Heravi, S. Asadi, 
Tetrahedron: Asymmetry 2012, 23, 1431-1465; i) G. Guillena, in Modern Methods in Stereoselective Aldol Reactions, WileyVCH Verlag GmbH \& Co. KGaA, 2013, pp. 155-268; j) J. Mlynarski, S. Bas, Chem. Soc. Rev. 2014, 43, $577-587$.

[3] B. List, R. A. Lerner, C. F. Barbas, J. Am. Chem. Soc. 2000, 122, 2395-2396.

[4] B. Alcaide, P. Almendros, Angew. Chem. Int. Ed. 2008, 47, 4632-4634.

[5] a) Y. Hayashi, T. Itoh, S. Aratake, H. Ishikawa, Angew. Chem. Int. Ed. 2008, 47, 2082-2084; b) Y. Hayashi, S. Samanta, T. Itoh, H. Ishikawa, Org. Lett. 2008, 10, 5581-5583.

[6] S. Hu, L. Zhang, J. Li, S. Luo, J.-P. Cheng, Eur. J. Org. Chem. 2011, 3347-3352.

[7] Y. Qiao, Q. Chen, S. Lin, B. Ni, A. D. Headley, J. Org. Chem. 2013, 78, 2693-2697.

[8] M. Kumar, B. A. Shah, S. C. Taneja, Adv. Synth. Catal. 2011, 353, 1207-1212.

[9] For the development of recyclable, heterogenized diarylprolinol ethers and selected applications, see: a) E. Alza, M. A. Pericàs, Adv. Synth. Catal. 2009, 351, 3051-3056.; b) E. Alza, S. Sayalero, P. Kasaplar, D. Almaşi, M. A. Pericàs Chem. Eur. J. 2011, 17, 11585-11595; c) E. Alza, S. Sayalero, X. C. Cambeiro, R. Martin-Rapun, P. O. Miranda, M. A. Pericàs, Synlett 2011, 464-468; d) P. Riente, C. Mendoza, M. A. Pericàs, J. Mater. Chem. 2011, 21, 7350-7355; e) X. Fan, S. Sayalero, M. A. Pericàs, Adv. Synth. Catal. 2012, 354, 2971-2976.

[10] For "wolf-and-lamb" reactions, see: a) B. J. Cohen, M. A. Kraus, A. Patchornik, J. Am. Chem. Soc. 1981, 103, 76207629; b) T. H. Maugh, Science 1982, 217, 719-720.

[11] X. Fan, C. Rodríguez-Escrich, S. Sayalero, M. A. Pericàs, Chem. Eur. J. 2013, 19, 10814-10817.

[12] For selected applications of site isolation, see: a) S. Hecht, J. M. J. Fréchet, Angew. Chem. Int. Ed. 2001, 40, 74-91; b) B. Voit, Angew. Chem. Int. Ed. 2006, 45, 4238-4240; c) K. Motokura, N. Fujita, K. Mori, T. Mizugaki, K. Ebitani, K. Kaneda, J. Am. Chem. Soc. 2005, 127, 9674-9675; d) B. Helms, S. J. Guillaudeu, Y. Xie, M. McMurdo, C. J. Hawker, J. M. J. Fréchet, Angew. Chem. Int. Ed. 2005, 44, 6384-6387; e) M. B. Runge, M. T. Mwangi, A. L. Miller, M. Perring, N. B. Bowden, Angew. Chem. Int. Ed. 2008, 47, 935-939.f) Y. Chi, S. T. Scroggins, J. M. J. Fréchet, J. Am. Chem. Soc. 2008, $130,6322-6323$.

[13] For water effect in aldol reaction, see: a) A. P. Brogan, T. J. Dickerson, K. D. Janda, Angew. Chem. Int. Ed. 2006, 45, 8100-8102; b) N. Zotova, A. Franzke, A. Armstrong, D. G. Blackmond, J. Am. Chem. Soc. 2007, 129, 15100-15101; c) A. K. Sharma, R. B. Sunoj, Angew. Chem. Int. Ed. 2010, 49, 6373-6377; d) J. Ribas-Arino, M. A. Carvajal, A. Chaumont, M. Masia, Chem. Eur. J. 2012, 18, 15868-15874; e) S. Paladhi, J. Das, P. K. Mishra, J. Dash, Adv. Synth. Catal. 2013, 355, 274-280; f) Z.-B. Xie, N. Wang, L.-H. Zhou, F. Wan, T. He, Z.-G. Le, X.-Q. Yu, ChemCatChem 2013, 5, 1935-1940.

[14] K. A. De Castro, J. Ko, D. Park, S. Park, H. Rhee, Org. Process Res. Dev. 2007, 11, 918-921.

[15] M. Sasikumar, M. D. Nikalje, Synth. Commun. 2012, 42, 3061-3067.

[16] G. Sabitha, P. Padmaja, J. S. Yadav, Helv. Chim. Acta 2008, 91, 2235-2239.

[17] C.-F. Xu, C.-Y. Yuan, Chin. J. Chem. 2004, 22, 775-778.

[18] a) V. Ratovelomanana-Vidal, C. Girard, R. Touati, J. P. Tranchier, B. B. Hassine, J. P. Genêt, Adv. Synth. Catal. 2003, 345, 261-274; b) H. Kakei, T. Nemoto, T. Ohshima, M. Shibasaki, Angew. Chem. Int. Ed. 2004, 43, 317-320; c) Â. de Fátima, A. A. M. Lapis, R. A. Pilli, J. Braz. Chem. Soc. 2005, 16, 495-499; d) D. Liu, W. Gao, C. Wang, X. Zhang, Angew. Chem. Int. Ed. 2005, 44, 1687-1689; e) R. K. Rej, T. Das, S. Hazra, S. Nanda, Tetrahedron: Asymmetry 2013, 24, 913-918.

[19] Y. Gao, K. B. Sharpless, J. Org. Chem. 1988, 53, 4081-4084.

[20] a) P. I. Dalko, L. Moisan, Angew. Chem. Int. Ed. 2001, 40, 3726-3748; b) K. N. Houk, B. List, Acc. Chem. Res. 2004, 37, 487-487; c) P. I. Dalko, L. Moisan, Angew. Chem. Int. Ed. 2004, 43, 5138-5175; d) S. Bertelsen, K. A. Jørgensen, Chem. Soc. Rev. 2009, 38, 2178-2189; e) D. W. C. MacMillan, Nature 2008, 455, 304-308.

[21] For synthesis of racemic Phenoperidine and its physiological activity studies, see: a) C. L. Duc, C. Charlon, C. A. Delord, J. Cros, B. Monsarrat, J. Labelled Compd. Radiopharm. 1978, 15, 693-696; b) M. Fischler, J. C. Levron, H. Trang, J. F. Vaxelaire, B. Flaisler, G. Vourch, Brit. J. Anaesth. 1985, 57, 872-876; c) M. Fischler, J. C. Levron, H. Trang, D. Brodaty, C. Dubois, D. Guilmet, G. Vourch, Brit. J. Anaesth. 1985, 57, 877-882.

[22] An attempt to purify $3 \mathrm{e}$ by chromatography failed, probably due to decomposition of this hydroxy aldehyde on silica gel. 